\title{
A Study of Mechanical Properties of Vibration Assisted Arc Welding Joint
}

\author{
Mahmudul H. Pavel, Nuruzzaman Rakib, Mohammad A. Habib, Ahmed Y. Sanin, and Asif Salman
}

\begin{abstract}
Welding is one of the major aspects of manufacturing as well as mechanical engineering. The strength of the metal joint depends on the type of welding used. Quality of metal joining strength can be improved with a few changes in the regular welding process. A few factors that improve metal jointing strength during the arc welding process had been studied in this paper. Research in welding process shows that Vibration can improve mechanical properties of the joining section. However, welding joint quality varies with different ranges of parameters in different conditions. To analyze those ranges of parameters in some selected conditions, a study has been performed in this paper. Some input parameters like vibration amplitude, vibration frequency, welding speed and electrode angle are selected to analyze the variation in the welded joint. For analyzing the results, output parameters -bending strength and dilution rate are calculated. It has been found that if all input parameters are kept in a selected range then output parameters -bending strength, the percentage of dilution increases than the regular case. Finally, it can be shown that Bending strength and percentage of dilution of a metal joint assisted with vibration shows the better result than without vibration.
\end{abstract}

Index Terms-Vibration Assisted Welding; Vibration Amplitude; Vibration Frequency; Welding Speed; Electrode Angle; Bending Strength; Dilution Rate.

\section{INTRODUCTION}

Welding is an ancient art which has been in use since the Bronze Age. It produces a secure, strong joint that is stronger than other methods of bonding metals. Welders ply their trade in a number of different industries, including construction, mining, oil, and automotive, to name a few. Filler material is typically added to strengthen the joint. Welding is a dependable, efficient and economical method for permanently joining similar metals. In arc welding, vibration can be applied either during or after the process. When applied after welding, it is generally termed as vibration stress relief, which is a stress relieving method in which controlled vibrations are being applied on welded pieces after welding. Continuing the search for higher productivity, researchers are now putting their effort to develop the process of arc welding during vibration, i.e. vibration assisted welding (VAW), which can cut most of

Published on March 21, 2018.

M. H. Pavel is an assistant Engineer at Confidence Power Holdings Limited (e-mail: mhasan13@iut-dhaka.edu).

N. Rakib is a graduate from Islamic University of Technology. (e-mail: rakibzaman1463@gmail.com)

M. A. Habib is an assistant professor of Mechanical department at Islamic University of Technology. (e-mail: mahabib@iut-dhaka.edu)

A. Y. Sanin is a graduate from Islamic University of Technology (email: ay.sanin@gmail.com).

A. Salman is a graduate from Islamic University of Technology (sachee91@gmail.com) the expenses related to post weld vibrations or heat treatments. Production lead time can be considerably reduced due to the parallel processing of vibration and welding. Moreover, VAW leads to improved microstructure [1] and better mechanical properties [2]. There are different modes in which vibration is applied to the workpiece such as longitudinal, transverse, vertical and random vibrations. In their oldest available paper, Tewari and Shanker [3] reported the effect of longitudinal vibration on mechanical properties such as yield strength, ultimate tensile strength and hardness. They reported that significant enhancement of mechanical properties was observed within the range of 80 $400 \mathrm{~Hz}$ for frequency and 5-30 $\mathrm{mm}$ for amplitude. In another investigation, breaking strength, ultimate tensile strength (UTS) and yield strength of specimen made under longitudinal vibratory conditions registered an improvement of [4]-[5] and 2\% respectively [6]. Electromagnetic stirring of molten pool was found to be favoring the grain refinement in gas tungsten arc (GTA) welds of thin sheet made of aluminum alloys [7]. The electromagnetic stirring apparatus had a magnetic coil with a ferrous core at the canter. The coil was fixed under the specimen and in line with the axis of welding torch. The mode of metal transfer has a lot of influence on the quality of welds. Pulsed current Gas Metal Arc Welding (GMAW) is a way to achieve controlled metal transfer. An analytical model was developed for explaining the droplet oscillation and detachment process in pulsed current GMAW [8] - [9]. The oscillation of arc welding was proved to be another method of generating agitations in weld pool. A two-dimensional mathematical model was developed to study the effect of electromagnetically oscillated arc on the microstructure and temperature distribution of bead on plate welds on thin tantalum sheets made through GTA Welding [10]. The ultrasonically vibrated welding electrode could produce more arc pressure in TIG welding [11]. The electrode vibrated axially, and the vibrations were passed on to weld pool through arc plasma. The ultrasonic vibrations created using an ultrasonic generator was transmitted to welding torch through a mechanical coupling and bead on plate welding was carried out on stainless steel pieces.

Though many studies have been done to find out the variation of results between vibration assisted welding and regular welding without vibration, but since today, very few Vibration-assisted welding experiments have been done using ranges of different parameters. Here, some input parameters like vibration amplitude, vibration frequency, welding speed and electrode angle are selected to analyze the variation in the welded joint. For analyzing the results, output parameters - bending strength and dilution are selected. In this study, the main purpose is to analyze the 
changes of mechanical properties like bending strength and percentage of dilution of the joining section of the metals with the addition of vibration on the metal joining point during arc welding process.

\section{EXPERIMENTAl SETUP AND Methodology}

\section{A. Concept and setup}

First, a wooden frame of the experiment has been made. This wooden frame includes a large table over which all the accessories like base table, a large wooden plate for vertically up and down movement, nylon rack and pinion, pulley, and motors are attached.

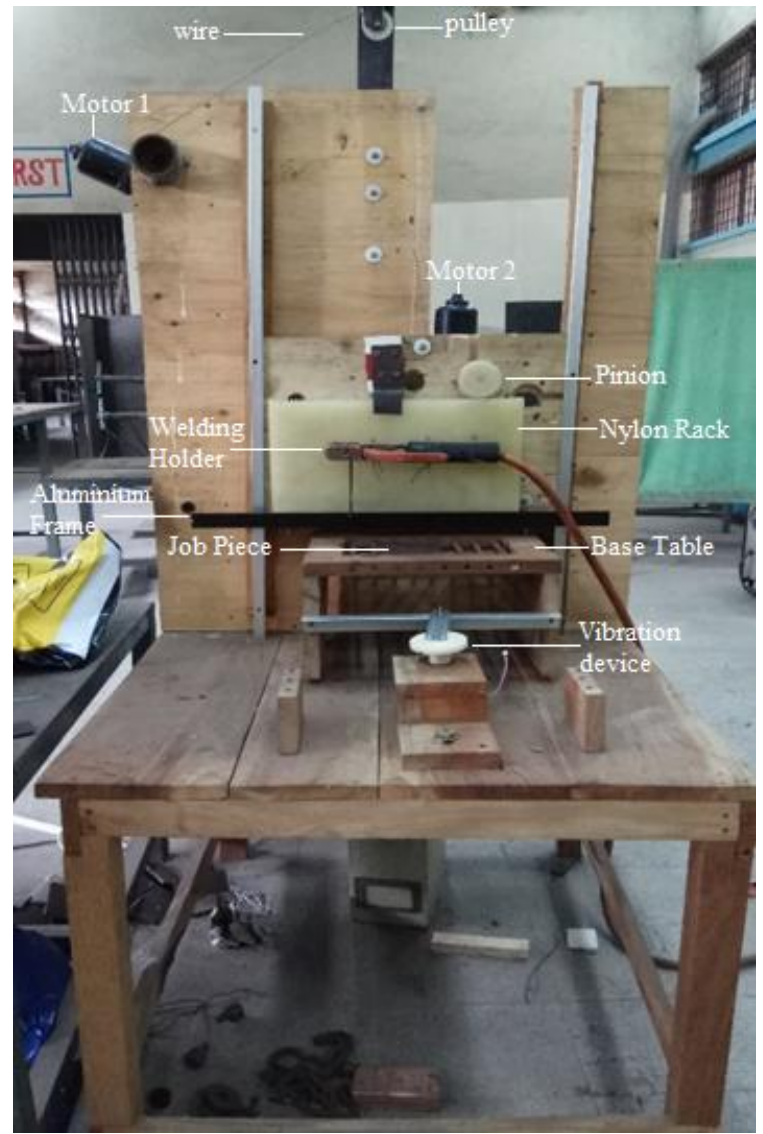

Fig. 1. Experimental setup

On the wooden plate, there is a pulley and the pulley is controlled by a dc $12 \mathrm{~V}$ motor. By this connection, that wooden plate can move upward and downward. On that plate, there is a pinion made of Nylon. A Nylon rack is set on an aluminum frame which is connected to the wooden frame. Rack and pinion have meshed together, that is why this connection can move back and forth. On that nylon rack, welding holder is connected. The vertical wooden plate has space in front of it, where the small wooden base table is kept. This wooden base table has a square hole where metallic rods are placed. At that place, job piece will be kept for the experiment. The Metallic rods are placed over there because earthling point should be maintained for welding. The sidewall of the small base table is connected with two springs with the main table. The small base table has four wheels and those wheels can roll on two rail lines. One vibration device is established in front of that small base plate. This arrangement allows the base table and the job piece to vibrate in back and forth direction. The system is made fully automatic by using an Arduino microcontroller and relay circuits to neutralize the effect of experimental error. The experimental setup and vibration system are shown in Fig. 1 and Fig. 2.

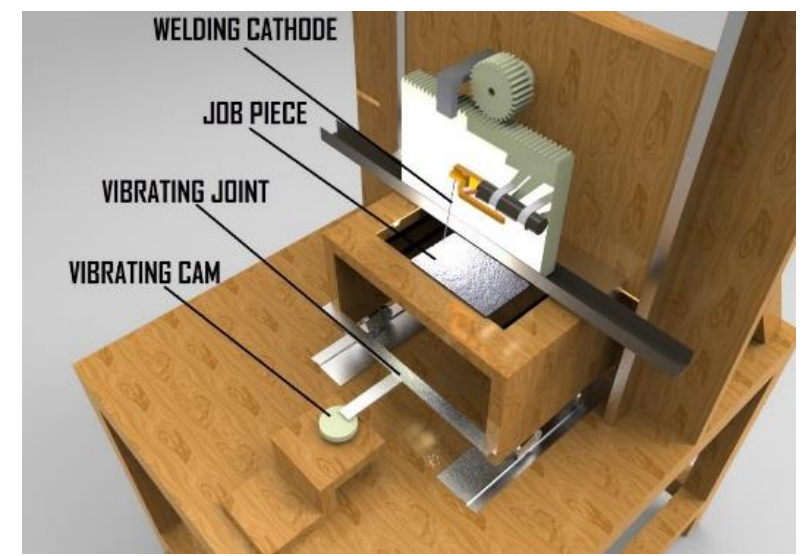

Fig. 2. Vibration system of the experiment designed by CAD software

\section{B. Methodology}

This experiment of the welding process is done to analyze the change of the mechanical properties of welding joining point. At first, it has been selected that which of the parameters have the great effect on the joining point of welded materials. Those selected input parameters are Vibration amplitude, Vibration frequency, Welding speed and Electrode angle. Experimental design is widely used for controlling the effects of parameters in many processes. Its usage decreases the number of experiments, using time and material resources. A full factorial design requires at least three levels per variable to estimate the coefficients of the quadratic terms in the response model. Thus for the four independent variables, 81 experiments plus replications would have to be conducted which is reduced by the Central Composite Design Software (CCD). For all parameters, five levels of data using CCD is used (Table I). Total thirty experiments are conducted, where 24 of them are non-center points and 6 of them are center points.

TABLE I: PROCESS PARAMETERS WITH THEIR VALUES AT DIFFERENT LEVELS

\begin{tabular}{|c|c|c|c|c|c|c|}
\hline \multirow{2}{*}{\multicolumn{2}{|c|}{ Parameters }} & \multicolumn{5}{|c|}{ Levels } \\
\hline & & \multirow{2}{*}{$\begin{array}{l}-\sqrt{2} \\
12.9\end{array}$} & \multirow{2}{*}{$\begin{array}{c}-1 \\
15.0\end{array}$} & \multirow{2}{*}{$\begin{array}{c}\mathrm{O} \\
20.0\end{array}$} & \multirow{2}{*}{$\begin{array}{c}+1 \\
25.0\end{array}$} & \multirow{2}{*}{$\begin{array}{l}+\sqrt{2} \\
27.1\end{array}$} \\
\hline $\begin{array}{l}\text { Vibration } \\
\text { amplitude } \\
(\mu \mathrm{m})\end{array}$ & $\mathbf{V}_{\mathbf{A}}$ & & & & & \\
\hline Vibration & & & & & & \\
\hline $\begin{array}{c}\text { Frequency } \\
(\mathrm{Hz})\end{array}$ & $\mathbf{V}_{\mathbf{F}}$ & 79.29 & 100.0 & 150.0 & 200.0 & 220.7 \\
\hline $\begin{array}{l}\text { Welding } \\
\text { speed } \\
(\mathrm{mm} / \mathrm{sec})\end{array}$ & $\mathbf{W}_{\mathrm{S}}$ & 1.4 & 2.0 & 3.5 & 5.0 & 5.6 \\
\hline $\begin{array}{l}\text { Electrode } \\
\text { Angle }\left(^{\circ}\right)\end{array}$ & $\mathbf{E}_{\mathrm{A}}$ & 11.9 & 15.0 & 22.5 & 30.0 & 33.1 \\
\hline
\end{tabular}

To compare the vibration results with non-vibration welding, 10 separate experiments are conducted (Table II). After completing the welding process, workpieces are taken 
to analyze for the changing of the mechanical properties of the joining point. With the help of a Universal testing machine, every specimen is tested and bending strength is noted down. Dilution calculation is one of the difficult parts of this experiment. Because this small amount of area cannot be easily calculated. For this calculation, another software "ImageJ" has been used. After taking the picture of all specimens, those are imported in this software one by one and calculated the percentage of dilution in the welded area.

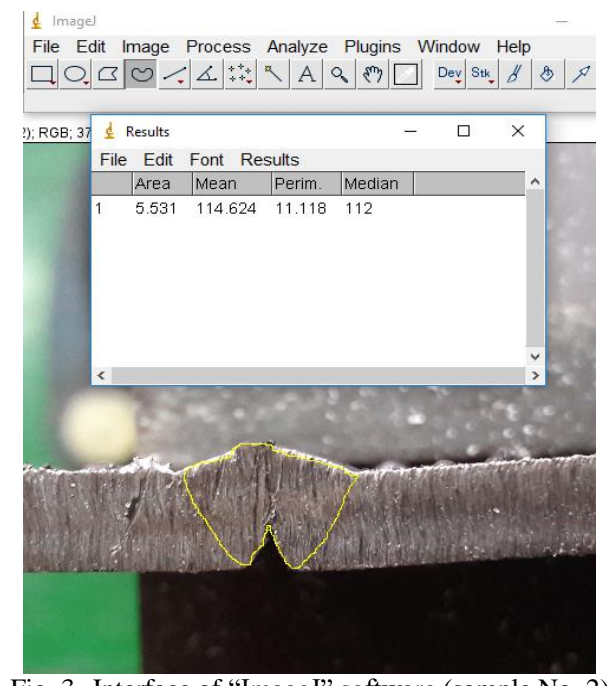

Fig. 3. Interface of "ImageJ" software (sample No. 2)

Mild steel bars are used as the workpiece. For these experiments, $2.5 \mathrm{~mm}$ filler rod is used. All the experiments are repeated five times to get an average data. The average bending strength and percentage dilution rate for different conditions are given in Table II (without vibration) and Table III (with vibration).

TABLE II: EXPERIMENTAL RESULTS FOR WITHOUT VIBRATION OR OSCILLATION

\begin{tabular}{ccccccc}
\hline \hline & \multicolumn{3}{c}{ Input parameters } & & \multicolumn{2}{c}{$\begin{array}{c}\text { Output parameters } \\
\text { (Experimental) }\end{array}$} \\
\cline { 2 - 7 } o. & $\mathbf{V}_{\mathbf{A}}$ & $\mathbf{V}_{\mathbf{F}}$ & $\mathbf{W}_{\mathbf{S}}$ & $\mathbf{E}_{\mathbf{A}}$ & $\begin{array}{c}\text { Bending } \\
\text { strength } \\
(\text { HRC) }\end{array}$ & $\begin{array}{c}\text { Dilution } \\
(\%)\end{array}$ \\
\hline 1 & 0 & 0 & 1.4 & 15.0 & 15.0 & 26 \\
2 & 0 & 0 & 2 & 15.0 & 14.0 & 24 \\
3 & 0 & 0 & 3.5 & 15.0 & 12.0 & 21 \\
4 & 0 & 0 & 5 & 15.0 & 10.0 & 19 \\
5 & 0 & 0 & 5.6 & 15.0 & 9.0 & 18 \\
6 & 0 & 0 & 2 & 11.9 & 16.0 & 25 \\
7 & 0 & 0 & 2 & 15.0 & 14.0 & 24 \\
8 & 0 & 0 & 2 & 22.5 & 11.0 & 22 \\
9 & 0 & 0 & 2 & 30.0 & 9.0 & 20 \\
10 & 0 & 0 & 2 & 33.1 & 8.0 & 19 \\
\hline \hline
\end{tabular}

TABLE III: EXPERIMENTAL RESULTS FOR WITH VIBRATION OR OSCILLATION

\begin{tabular}{|c|c|c|c|c|c|c|}
\hline \multirow{2}{*}{$\begin{array}{l}\mathrm{N} \\
\mathrm{o}\end{array}$} & \multicolumn{4}{|c|}{ Input parameters } & \multicolumn{2}{|c|}{$\begin{array}{l}\text { Output parameters } \\
\text { (Experimental) }\end{array}$} \\
\hline & $\mathbf{V}_{\mathbf{A}}$ & $\mathbf{V}_{\mathbf{F}}$ & $\mathbf{W}_{\mathbf{S}}$ & $\mathbf{E}_{\mathrm{A}}$ & $\begin{array}{l}\text { Bending } \\
\text { Strength }\end{array}$ & $\begin{array}{l}\text { Dilution } \\
(\%)\end{array}$ \\
\hline 1 & 15.0 & 100.0 & 2.0 & 15.0 & 13.20 & 34.0 \\
\hline 2 & 25.0 & 100.0 & 2.0 & 15.0 & 17.90 & 35.0 \\
\hline 3 & 15.0 & 200.0 & 2.0 & 15.0 & 17.80 & 38.0 \\
\hline 4 & 25.0 & 200.0 & 2.0 & 15.0 & 22.50 & 41.0 \\
\hline 5 & 15.0 & 100.0 & 5.0 & 15.0 & 8.60 & 26.0 \\
\hline 6 & 25.0 & 100.0 & 5.0 & 15.0 & 13.50 & 23.0 \\
\hline 7 & 15.0 & 200.0 & 5.0 & 15.0 & 13.20 & 30.0 \\
\hline 8 & 25.0 & 200.0 & 5.0 & 15.0 & 17.90 & 31.0 \\
\hline 9 & 15.0 & 100.0 & 2.0 & 30.0 & 8.60 & 22.0 \\
\hline 10 & 25.0 & 100.0 & 2.0 & 30.0 & 13.20 & 21.0 \\
\hline 11 & 15.0 & 200.0 & 2.0 & 30.0 & 13.40 & 32.0 \\
\hline 12 & 25.0 & 200.0 & 2.0 & 30.0 & 18.00 & 29.0 \\
\hline 13 & 15.0 & 100.0 & 5.0 & 30.0 & 4.00 & 10.0 \\
\hline 14 & 25.0 & 100.0 & 5.0 & 30.0 & 8.80 & 14.0 \\
\hline 15 & 15.0 & 200.0 & 5.0 & 30.0 & 8.60 & 22.0 \\
\hline 16 & 25.0 & 200.0 & 5.0 & 30.0 & 13.00 & 23.0 \\
\hline 17 & 12.9 & 150.0 & 3.5 & 22.5 & 8.60 & 19.0 \\
\hline 18 & 27.1 & 150.0 & 3.5 & 22.5 & 13.3 & 21.0 \\
\hline 19 & 20.0 & 79.29 & 3.5 & 22.5 & 8.6 & 23.0 \\
\hline 20 & 20.0 & 220.7 & 3.5 & 22.5 & 17.8 & 39.0 \\
\hline 21 & 20.0 & 150.0 & 1.4 & 22.5 & 17.5 & 42.0 \\
\hline 22 & 20.0 & 150.0 & 5.6 & 22.5 & 8.60 & 17.0 \\
\hline 23 & 20.0 & 150.0 & 3.5 & 11.9 & 13.40 & 32.0 \\
\hline 24 & 20.0 & 150.0 & 3.5 & 33.1 & 8.6 & 23.0 \\
\hline 25 & 20.0 & 150.0 & 3.5 & 22.5 & 13.20 & 29.0 \\
\hline 26 & 20.0 & 150.0 & 3.5 & 22.5 & 13.10 & 30.0 \\
\hline 27 & 20.0 & 150.0 & 3.5 & 22.5 & 13.30 & 31.0 \\
\hline 28 & 20.0 & 150.0 & 3.5 & 22.5 & 13.00 & 30.0 \\
\hline 29 & 20.0 & 150.0 & 3.5 & 22.5 & 13.40 & 31.0 \\
\hline 30 & 20.0 & 150.0 & 3.5 & 22.5 & 34.20 & 29.0 \\
\hline
\end{tabular}

\section{Mathematical Model}

For developing the mathematical model, first, the fitness function for the output parameters are calculated. To find out the fitness function the natural $\log$ transformation is selected and quadratic type equation is used for this case. By using these conditions, the ANOVA (analysis of variance) for response surface quadratic model shows significant behavior and for lack of fit, it shows non-significant behavior. This proves that the fitness equation is working within the reasonable range. Using Design Expert 7.00 software, ANOVA output and model equation is found for every output Parameters-Bending strength, Dilution rate.

The model (Eq. 1 and 2) as suggested for the Bending strength and Dilution percentage by the fit and summary tests is shown below:

$\ln ($ Bending Strength $)=2.83267+.021641 \times V_{A}+3.58006 \times$ $10^{-3} \times V_{F}-.24062 \times W_{D}-.049555 \times E_{A}-1.81305 \times 10^{-4} \times V_{A} V_{F}+$ $5.78903 \times 10^{-3} \times V_{A} W_{D}+1.05134 \times 10^{-3} \times V_{A} E_{A}+4.87406 \times 10^{-4} \times$ $V_{F} W_{D}+1.11842 \times 10^{-4} \times V_{F} E_{A}-3.89770 \times 10^{-3} \times W_{D} E_{A}$ 
$\ln ($ Dilution $)=2.55566+.24876 \times V_{A}-7.82848 \times 10^{-3} \times V_{F}-$ $0.17037 \times W_{D}-.047886 \times E_{A}-3.53875 \times 10^{-5} \times V_{A} V_{F}+2.75915 \times$ $10^{-3} \times V_{A} W_{D}+3.68005 \times 10^{-4} \times V_{A} E_{A}+6.32976 \times 10^{-4} \times V_{F} W_{D}+$ $2.11886 \times 10^{-4} \times V_{F} E_{A}-3.31292 \times 10^{-3} \times W_{D} E_{A}-6.43646 \times 10^{-3} \times$ $V_{A}^{2}+1.66453 \times 10^{-5} \times V_{F}^{2}-6.85794 \times 10^{-3} \times W_{D}^{2}-1.39441 \times$ $10^{-4} \times E_{A}^{2} \ldots \ldots$

Using the model equation equations, the output Parameters-Bending strength \& percentage dilution rate is calculated and compared with the experimental output values and percentage of error is calculated. For bending strength, only experiment no $18 \& 23$ have a percentage of error more than $10 \%$. For dilution rate experiment no- $\{5$, $12,13$, and 22$\}$ have a percentage of error more than $10 \%$. Except that all the percentage of error was less than $8 \%$.

\section{RESULTS AND DISCUSSION}

Generating the model equation, graphical representation is done to analyze the effect of input parameters on output.

\section{A. Effect of Vibrational Amplitude}

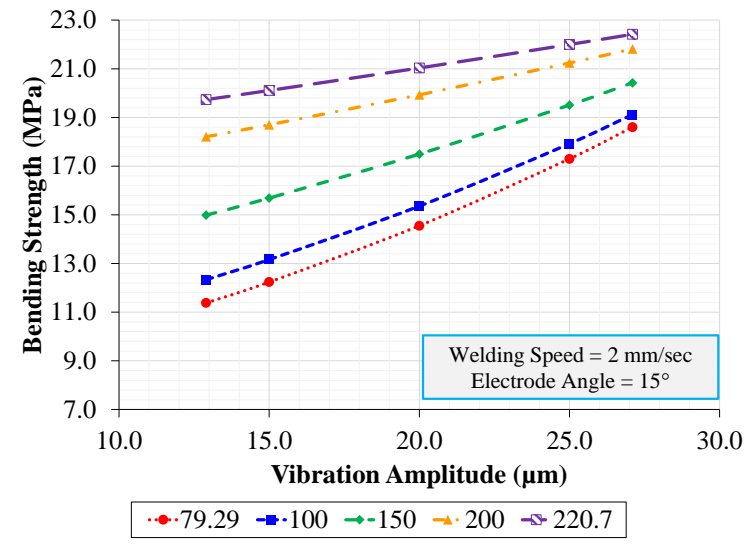

Fig. 4. Effect of vibration amplitude for different vibration frequency on bending strength

Fig. 4 shows bending strength curves are increasing with the increment of amplitude with different frequency. The increase of amplitude provides more penetration to the joining point because it helps the molten metal to enter into the lower depth of the joint. Bending strength varies with penetration quality. If penetration is high then bending strength is high and if it is low then so as bending strength. Fig. 5 (a) shows lower amplitude and frequency provides less penetration wherein Fig. 5 (b), high amplitude with high frequency provide almost complete penetration and stronger joint.

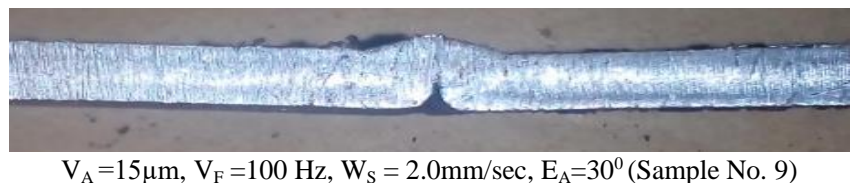

(a)

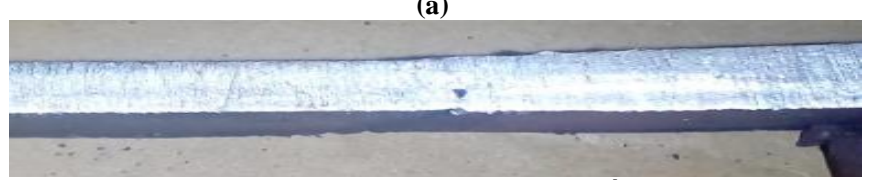

$\mathrm{V}_{\mathrm{A}}=25 \mu \mathrm{m}, \mathrm{V}_{\mathrm{F}}=200 \mathrm{~Hz}, \mathrm{~W}_{\mathrm{S}}=2.0 \mathrm{~mm} / \mathrm{sec}, \mathrm{E}_{\mathrm{A}}=30^{\circ}$ (Sample No. 12) (b)

Fig. 5. Higher penetration with the change of amplitude in welding (a) less penetration (b) complete penetration

Fig. 6 shows that at first dilution increases but after a certain point, it goes down but it can easily say that within $20-25 \mu \mathrm{m}$ amplitude with high frequency it provides better result.

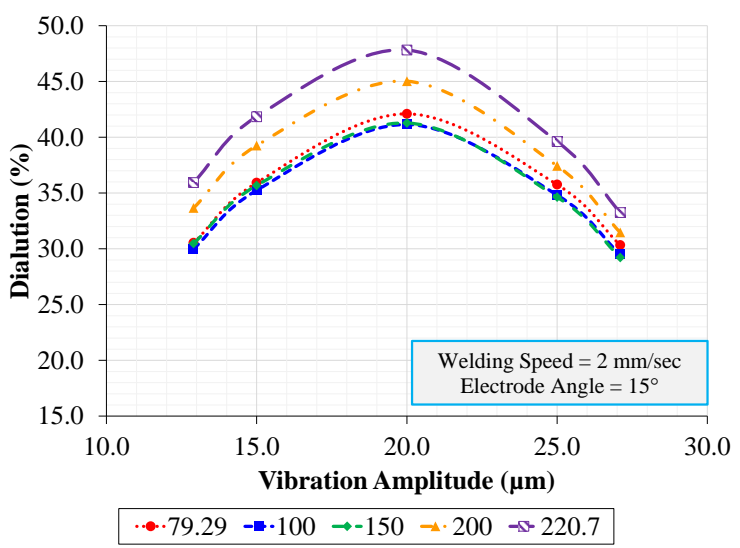

Fig. 6. Effect of vibration amplitude for different vibration frequency on Dilution

Fig. 7(a) shows low amplitude gives lower dilution percentage but Fig. 7 (b) indicates with high frequency high amplitude provides higher dilution percentage.

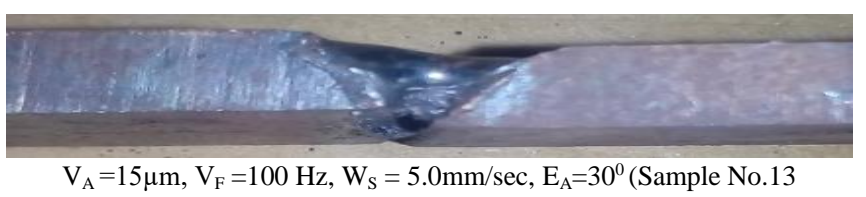
(a)

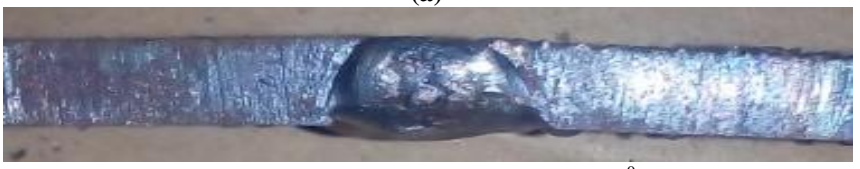

$\mathrm{V}_{\mathrm{A}}=20 \mu \mathrm{m}, \mathrm{V}_{\mathrm{F}}=150 \mathrm{~Hz}, \mathrm{~W}_{\mathrm{S}}=1.4 \mathrm{~mm} / \mathrm{sec}, \mathrm{E}_{\mathrm{A}}=22.5^{0}($ SampleNo. 21

(b)

Fig. 7. Change of dilution with the variation of vibration amplitude (a) less dilution (b) more dilution

\section{B. Effect of Vibration Frequency}

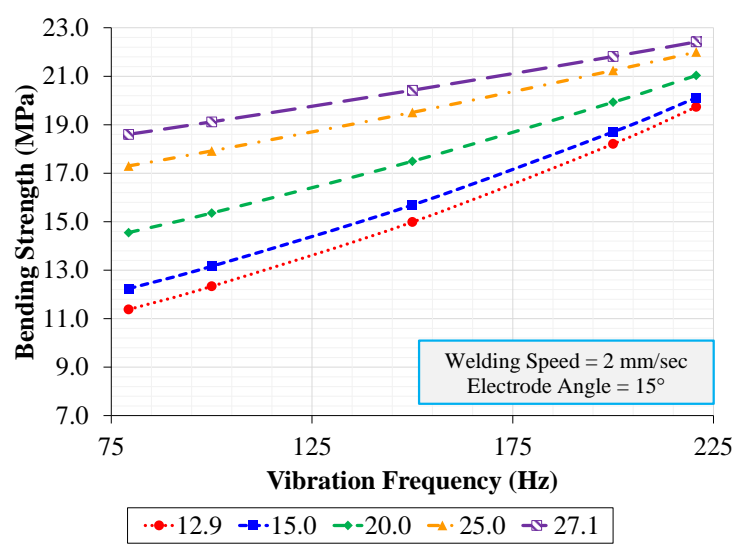

Fig. 8. Effect of vibration frequency for different vibration amplitude on bending strength

Fig. 8 also shows that frequency has a very significant role to improve the bending strength of the joining point 
Here bending strength increases with the increase of frequency. For getting more bending strength, it is necessary to increase the penetration of molten metal in joining point. Frequency helps to increase the penetration of molten metal. In Fig. 9(a), low frequency with less amplitude provides lower penetration than the high frequency with high amplitude shown in Fig. 9(b).

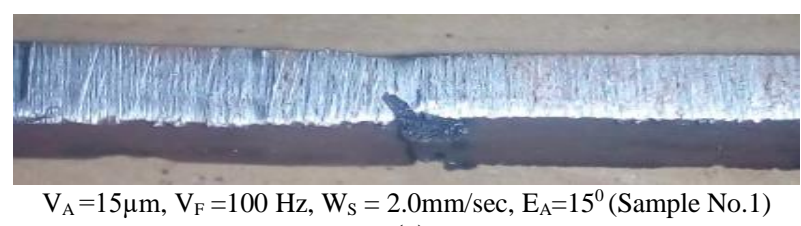

(a)

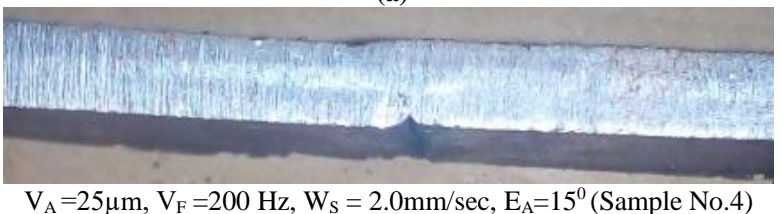

(b)

Fig. 9. Higher penetration in welding joint with the variation of frequency (a) low penetration (b) higher penetration

Fig. 10 also shows dilution of the joining point is also increasing with frequency and amplitude because having less porosity and more penetration, now molten metal can dilute more area of the job piece and create a strong bond.

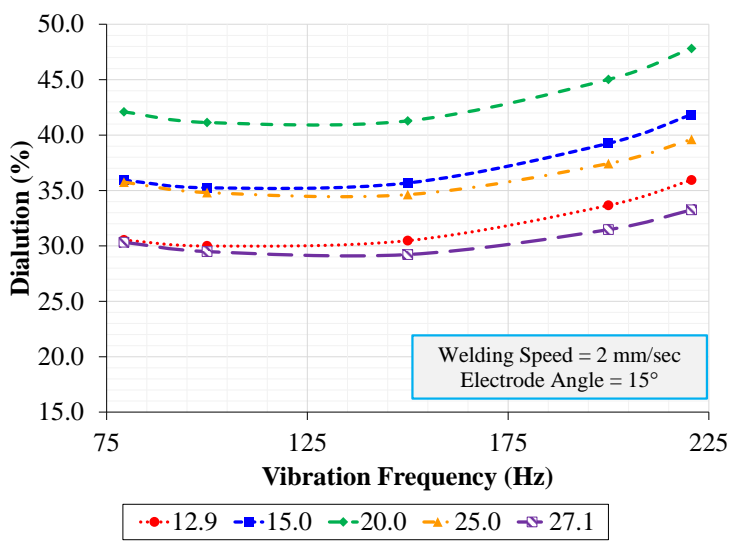

Fig. 10. Effect of vibration frequency for different vibration amplitude on Dilution

Dilution is lower with low frequency and amplitude shown in Fig. 11(a) but higher with high frequency and amplitude shown in Fig. 11(b).

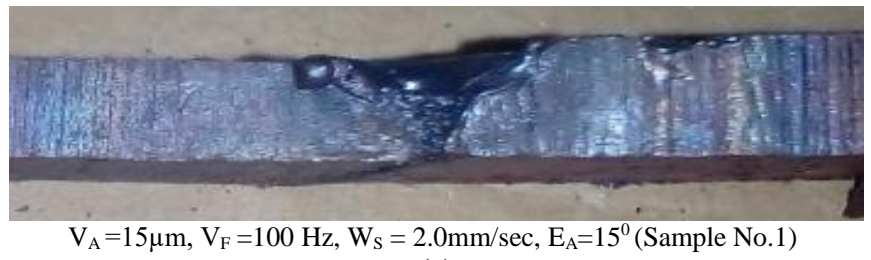

(a)

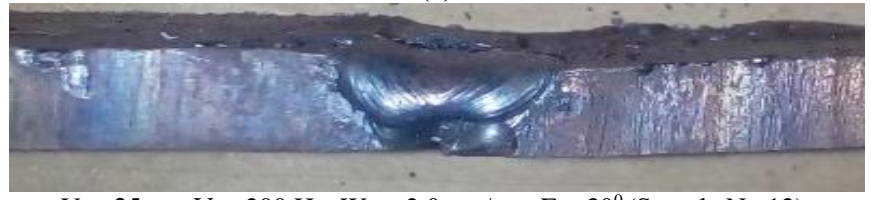

$\mathrm{V}_{\mathrm{A}}=25 \mu \mathrm{m}, \mathrm{V}_{\mathrm{F}}=200 \mathrm{~Hz}, \mathrm{~W}_{\mathrm{S}}=2.0 \mathrm{~mm} / \mathrm{sec}, \mathrm{E}_{\mathrm{A}}=30^{0}$ (Sample No.12)

(b)

Fig. 11. Change of dilution with the variation of vibration frequency (a) low dilution percentage (b) high dilution percentage

\section{Effect of Welding Speed}

Fig. 12 shows different colored lines of bending strength is decreasing with the increase of welding speed because molten metal does not get enough time to penetrate the joint. The Black colored line shows the changing without oscillation.

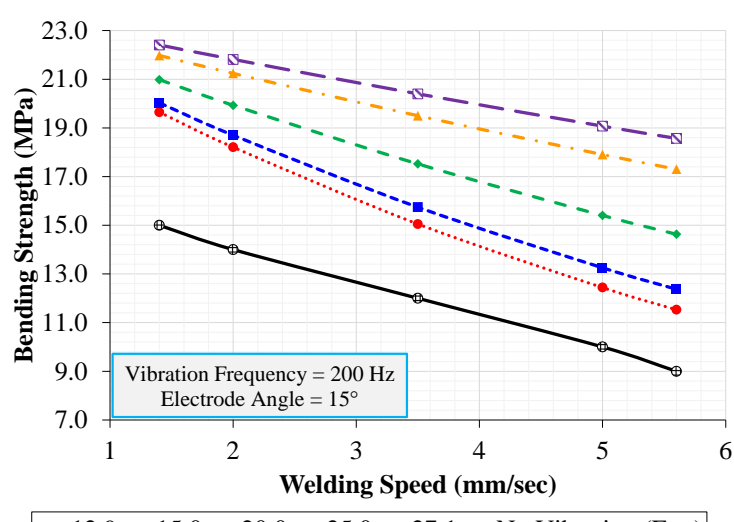

$\cdots \cdot 12.9 \rightarrow \cdot 15.0 \rightarrow-20.0 \rightarrow 25.0 \rightarrow 27.1 \rightarrow-$ No Vibration (Exp)

Fig. 12. Effect of welding speed for different vibration frequency on bending strength

Fig. 13(a) shows incomplete penetration due to high welding speed. On the other hand, Fig. 13(b) shows complete penetration due to less welding speed. Fig. 13(c) shows no oscillation gives less penetration at the welding joint.

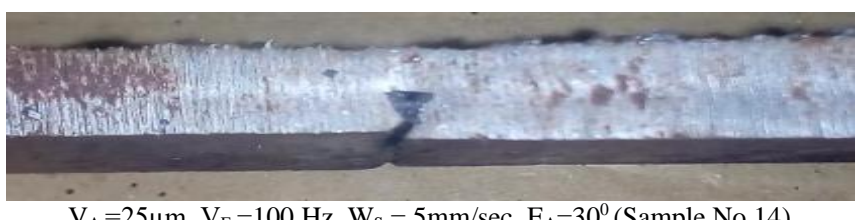

$\mathrm{V}_{\mathrm{A}}=25 \mu \mathrm{m}, \mathrm{V}_{\mathrm{F}}=100 \mathrm{~Hz}, \mathrm{~W}_{\mathrm{S}}=5 \mathrm{~mm} / \mathrm{sec}, \mathrm{E}_{\mathrm{A}}=30^{0}($ Sample No.14)

(a)

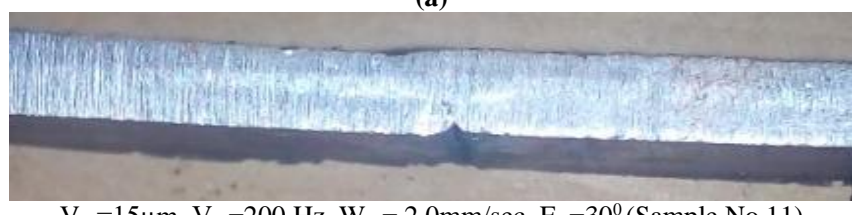

$\mathrm{V}_{\mathrm{A}}=15 \mu \mathrm{m}, \mathrm{V}_{\mathrm{F}}=200 \mathrm{~Hz}, \mathrm{~W}_{\mathrm{S}}=2.0 \mathrm{~mm} / \mathrm{sec}, \mathrm{E}_{\mathrm{A}}=30^{0}($ Sample No.11 $)$

(b)

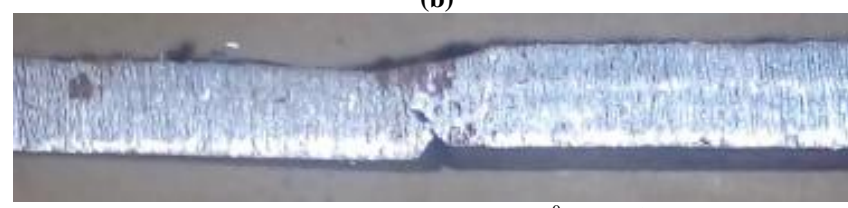

$\mathrm{V}_{\mathrm{A}}=0, \mathrm{~V}_{\mathrm{F}}=0, \mathrm{~W}_{\mathrm{S}}=5 \mathrm{~mm} / \mathrm{sec}, \mathrm{E}_{\mathrm{A}}=15^{0}($ Sample No.34)

(c)

Fig. 13. Change of penetration with welding speed (a) less penetration (b) high penetration (c) less penetration (no oscillation).

Fig. 14 shows less welding speed with high frequency and amplitude gives more dilution cause for higher penetration and less porosity in the joining point, more hot metal enters and it dilutes more area than without oscillation. Therefore, joining becomes stronger than normal welding process. Fig. 15 (a) shows lower dilution because of higher welding speed, which is gradually turned into higher dilution with less welding speed shown in Fig. 15(b). In Fig. 15(c), it shows dilution percentage is very low when the welding process is without oscillation. 


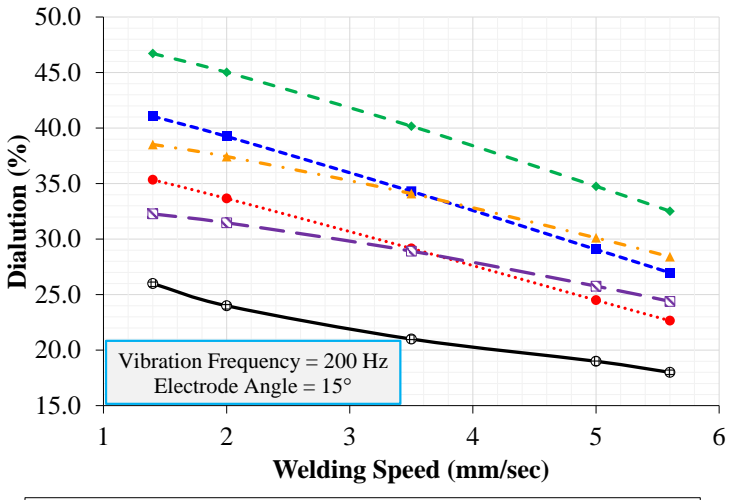

$\cdots \cdot 12.9-15.0 \rightarrow-20.0 \rightarrow 25.0 \rightarrow 27.1 \rightarrow-$ No Vibration $($ Exp)

Fig. 14. Effect of welding speed for different vibration frequency on Dilution

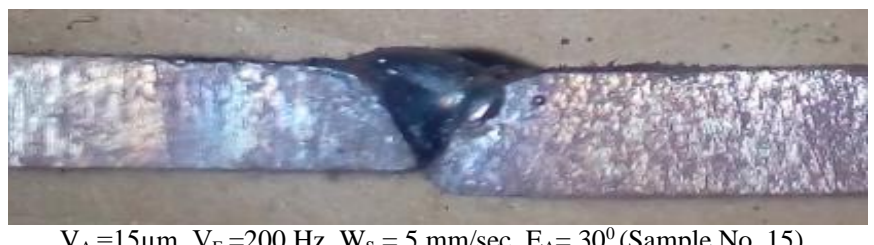

(a)

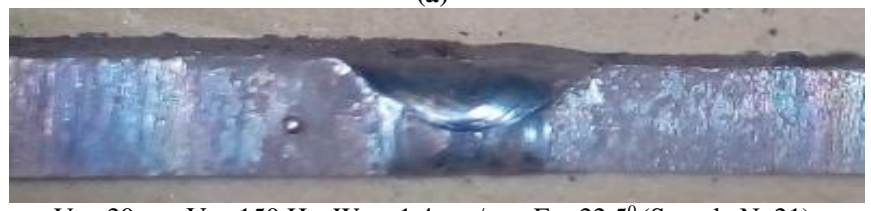

(b)

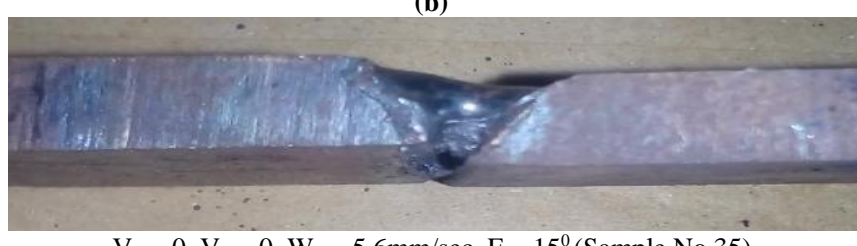

$\mathrm{V}_{\mathrm{A}}=0, \mathrm{~V}_{\mathrm{F}}=0, \mathrm{~W}_{\mathrm{S}}=5.6 \mathrm{~mm} / \mathrm{sec}, \mathrm{E}_{\mathrm{A}}=15^{0}($ Sample No.35)

(c)

Fig. 15. Change of dilution with the variation of welding speed (a) lower dilution (b) higher dilution (c) lower dilution (no oscillation).

\section{Effect of Electrode Angle}

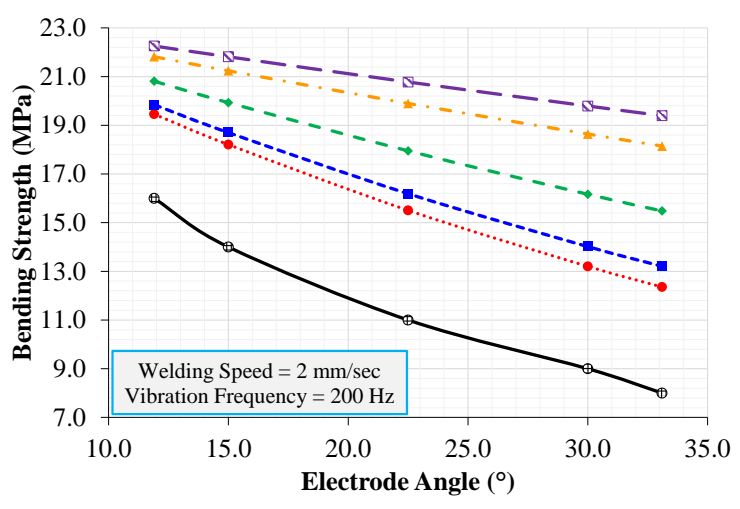

$\bullet 12.9 \rightarrow \cdot 15.0 \rightarrow-20.0 \rightarrow 25.0 \leadsto 27.1 \leadsto-$ No Vibration $($ Exp)

Fig. 16. Effect of electrode angle for different vibration frequency on bending strength

Fig. 16 represent that with high frequency and high amplitude, less electrode angle provides greater penetration in joining point. Because more metal is entering and metal is getting enough space to reach the lower point of the joint. Therefore, penetration increases, so the bending strength of this joint becomes high.
Fig. 17 (a) shows high electrode angle with low amplitude and frequency decreases bending strength but less electrode angle with high amplitude and frequency increases bending strength shown in Fig. 17(b). Fig. 17(c) shows the incomplete penetration when the welding process is without oscillation.

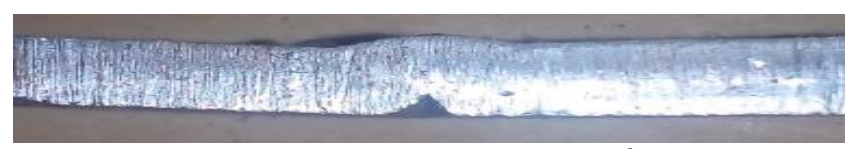

$\mathrm{V}_{\mathrm{A}}=20 \mu \mathrm{m}, \mathrm{V}_{\mathrm{F}}=150 \mathrm{~Hz}, \mathrm{~W}_{\mathrm{S}}=3.5 \mathrm{~mm} / \mathrm{sec}, \mathrm{E}_{\mathrm{A}}=33.1^{0}($ SampleNo.24) (a)

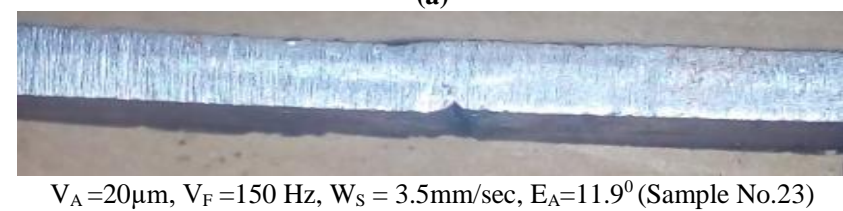

(b)

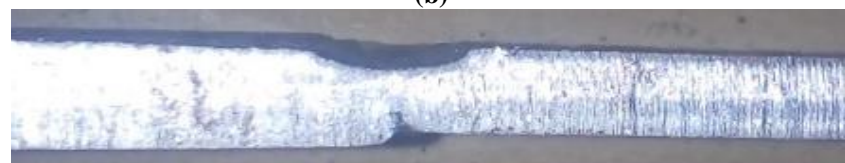

$\mathrm{V}_{\mathrm{A}}=0, \mathrm{~V}_{\mathrm{F}}=0, \mathrm{~W}_{\mathrm{S}}=2.0 \mathrm{~mm} / \mathrm{sec}, \mathrm{E}_{\mathrm{A}}=33.1^{0}($ Sample No.40)

(c)

Fig. 17. Penetration change with electrode angle (a) less penetration (b) high penetration (c) less penetration (no oscillation).

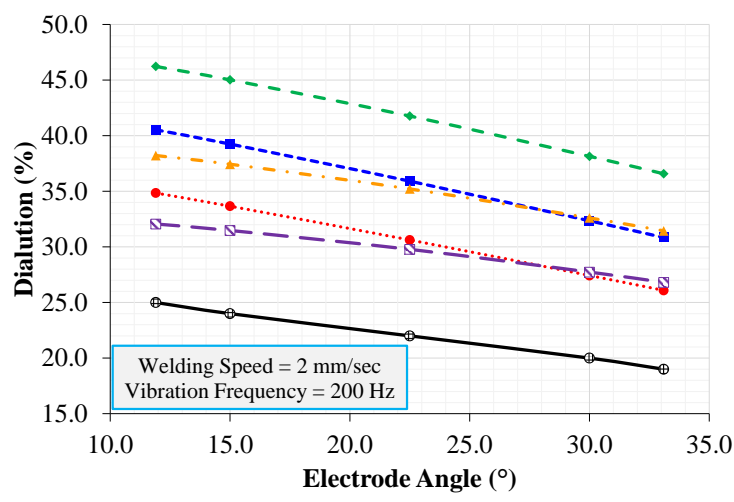

$\cdots \cdot 12.9-15.0 \rightarrow-20.0 \rightarrow 25.0 \rightarrow-\$ 27.1 \rightarrow-$ No Vibration $($ Exp)

Fig. 18. Effect of electrode angle for different vibration frequency on Dilution

Fig. 18 shows less electrode angle with high frequency, Amplitude and less welding speed gives more dilution cause for higher penetration and less porosity in the joining point, amount of hot metal increases into the joining point and so it can dilute more area than high electrode angle with oscillation. Fig. 19(a) shows welding with high electrode angle dilutes less area than welding with less electrode angle shown in Fig. 19 (b). In Fig. 19(c), it shows dilution percentage is very low when the welding process is without oscillation.

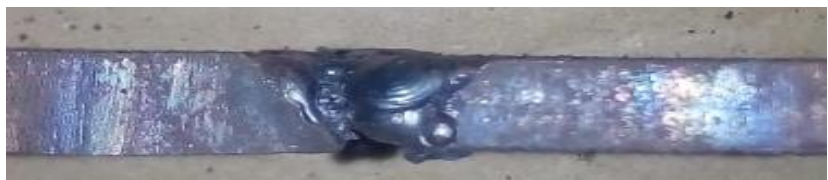

$\mathrm{V}_{\mathrm{A}}=20 \mu \mathrm{m}, \mathrm{V}_{\mathrm{F}}=150 \mathrm{~Hz}, \mathrm{~W}_{\mathrm{S}}=3.5 \mathrm{~mm} / \mathrm{sec}, \mathrm{E}_{\mathrm{A}}=33.1^{0}($ Sample No.24)

(a) 


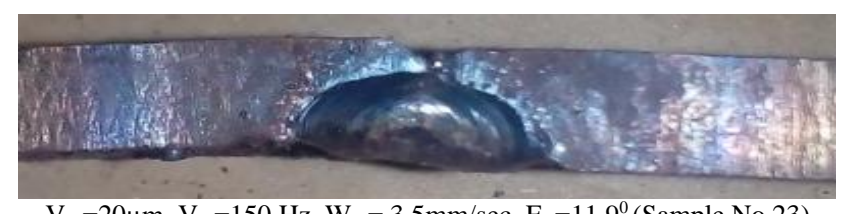

$\mathrm{V}_{\mathrm{A}}=20 \mu \mathrm{m}, \mathrm{V}_{\mathrm{F}}=150 \mathrm{~Hz}, \mathrm{~W}_{\mathrm{S}}=3.5 \mathrm{~mm} / \mathrm{sec}, \mathrm{E}_{\mathrm{A}}=11.9^{0}($ Sample No.23)

(b)

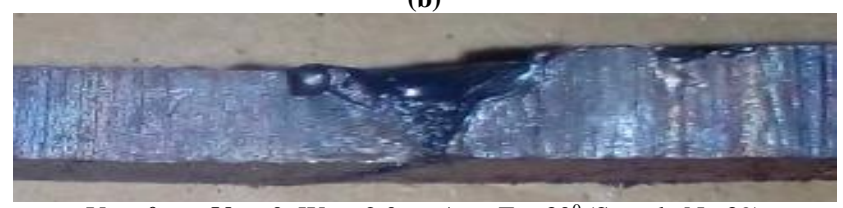

$\mathrm{V}_{\mathrm{A}}=0 \mu \mathrm{m}, \mathrm{V}_{\mathrm{F}}=0, \mathrm{~W}_{\mathrm{S}}=2.0 \mathrm{~mm} / \mathrm{sec}, \mathrm{E}_{\mathrm{A}}=30^{0}($ Sample No.39)

(c)

Fig. 19. Change of dilution with the variation of electrode angle (a) lower dilution (b) higher dilution (c) lower dilution (no oscillation)

\section{CONCLUSION}

From the above discussion, it can be easily said that the input parameters- Amplitude, Frequency, Welding speed, Electrode angle have a very significant effect on welding process. It can be concluded that

- Input and output parameters shows that Bending Strength of a welded joint increases with the increase of amplitude \& frequency but it decreases due to increase of Welding speed and Electrode angle.

- Vibration amplitude, frequency, welding speed and electrode angle control penetration level in the welded joint. These control input parameters in some specific ranges help to get complete penetration in joining the section, which provides the better joint than regular cases.

- Less welding speed, less electrode angle with high frequency and amplitude gives more dilution in the metal joint as for higher penetration and less porosity in the joining point, more hot metal enters and it dilutes more area than without oscillation.

\section{REFERENCES}

[1] Wu, W. (2005, February) "Mechanical behavior of the precision component after synchronous vibratory joining" In Micro-and Nanotechnology: Materials, Processes, Packaging, and Systems II (Vol. 5650, pp. 438-446). International Society for Optics and Photonics.

[2] Tewari, S. P. (1999) "Effects of Transverse Oscillation on Tensile Properties of Mild Steel Weldments" ISIJ international, 39(6), 570574.

[3] Tewari, S. P., \& Shanker, A. (1993) "Effects of longitudinal vibration on the mechanical properties of mild steel weldments" Proceedings of the Institution of Mechanical Engineers, Part B: Journal of Engineering Manufacture, 207(3), 173-177.

[4] Ju, J., Suga, Y., \& Ogawa, K. (2002, January) "Penetration control by monitoring molten pool oscillation in TIG arc welding" In The Twelfth International Offshore and Polar Engineering Conference. International Society of Offshore and Polar Engineers.

[5] Munsi, A. S. M. Y., Waddell, A. J., \& Walker, C. A. (1999) "Vibratory weld conditioning - the effect of rigid body motion vibration during welding" Strain, 35(4), 139-143.

[6] Tewari, S. P. (2009) "Influence of longitudinal oscillation on tensile properties of medium carbon steel welds of different thickness" Science \& Technology Asia, 14(4), 17-27.
[7] Matsuda, F., Nakagawa, H., Nakata, K., \& Ayani, R. (1978) "Effect of electromagnetic stirring on weld solidification structure of aluminum alloys (Report I): Investigation on GTA weld metal of thin sheet" Transactions of JWRI, 7(1), 111-127.

[8] Wu, C. S., Chen, M. A., \& Li, S. K. (2004) "Analysis of excited droplet oscillation and detachment in active control of metal transfer" Computational Materials Science, 31(1-2), 147-154.

[9] Chen, M. A., Wu, C. S., Li, S. K., \& Zhang, Y. M. (2007) "Analysis of active control of metal transfer in modified pulsed GMAW" Science and Technology of Welding and Joining, 12(1), 10-14.

[10] Grill, A. (1981) "Effect of arc oscillations on the temperature distribution and microstructure in GTA tantalum welds" Metallurgical Transactions B, 12(4), 667-674.

[11] 孙清洁, 林三宝, 杨春利, 范阳阳, \& 赵国庆. (2008) “The arc characteristic of ultrasonic assisted TIG welding” 中国焊接: 英文版, 17(4), 52-57.

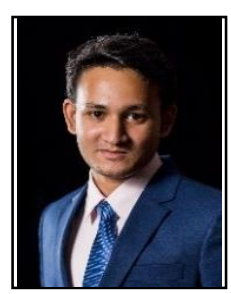

Mahmudul Hasan Pavel completed his B.Sc. in Mechanical Engineering from Islamic University of Technology, Dhaka, Bangladesh on 15th November, 2017. Currently he is an assistant engineer of Confidence Power Holdings Ltd, Dhaka, Bangladesh. His field of research includes CAD, Manufacturing Process, Power plant engineering and renewable energy, modelling and controlling of drone

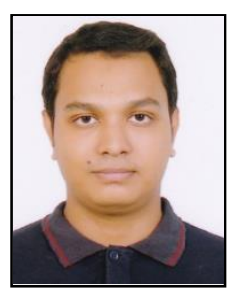

Nuruzzaman Rakib is a graduated Mechanical Engineer. He completed his graduation in Mechanical Engineering from Islamic University of Technology, Dhaka, Bangladesh. His field of research includes $\mathrm{CAD}, \mathrm{CAE}$ and Manufacturing Process.

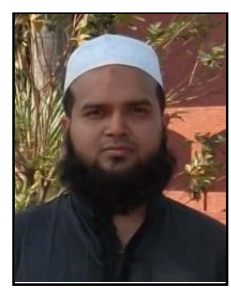

Mohammad Ahsan Habib is working as an Assistant Professor in the Department of Mechanical and Chemical Engineering of Islamic University of Technology, Dhaka, Bangladesh. He received his Ph. D. from National University of Singapore (NUS) in Engineering. His research interest in Conventional and Non-conventional Manufacturing Technique; Computer-aided Design, Engineering \& Manufacturing (CAD, CAE, CAM), Automobile and Mechatronics.

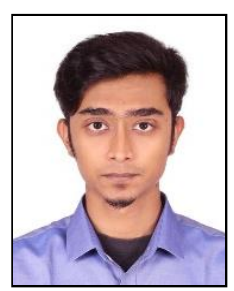

Ahmed Yousuf Sanin completed his B.Sc. in Mechanical Engineering from Islamic University of Technology, Dhaka, Bangladesh on 15th November, 2017. His field of research includes CAD, Manufacturing Process.

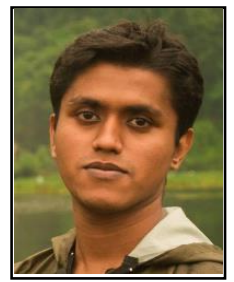

Asif Salman completed his M.Sc. in Mechanical Engineering from Islamic University of Technology, Dhaka, Bangladesh. He completed his B.Sc. in Mechanical Engineering from Islamic University of Technology, Dhaka, Bangladesh. His field of research includes CAD, Manufacturing Process 